\title{
Synthesis of Metal Oxide Decorated Polycarboxyphenyl Polymer-Grafted Multiwalled Carbon Nanotube Composites by a Chemical Grafting Approach for Supercapacitor Application
}

\author{
Do-Yeon Kang, ${ }^{1}$ Pashupati Pokharel, ${ }^{2}$ Yeong-Seok Kim, ${ }^{1}$ \\ Sunwoong Choi, ${ }^{2}$ and Seong-Ho Choi ${ }^{1}$ \\ ${ }^{1}$ Department of Chemistry, Hannam University, Daejeon 305-811, Republic of Korea \\ ${ }^{2}$ Department of Polymer Science and Engineering, Hannam University, Daejeon 305-811, Republic of Korea
}

Correspondence should be addressed to Seong-Ho Choi; shchoi@hnu.kr

Received 5 January 2015; Revised 16 March 2015; Accepted 19 March 2015

Academic Editor: Zhonghua Xiang

Copyright (c) 2015 Do-Yeon Kang et al. This is an open access article distributed under the Creative Commons Attribution License, which permits unrestricted use, distribution, and reproduction in any medium, provided the original work is properly cited.

We present grafting of polycarboxyphenyl polymer on the surface of multiwalled carbon nanotube (MWCNT) via a free radical polymerization and subsequent anchoring of the metal oxide nanoparticles for the evaluation of their potential applicability to supercapacitor electrodes. Here, metal oxide nanoparticles, $\mathrm{Fe}_{3} \mathrm{O}_{4}$ and $\mathrm{Sm}_{2} \mathrm{O}_{3}$, were created after the oxidation of metal precursors $\mathrm{Sm}\left(\mathrm{NO}_{3}\right)_{3}$ and $\mathrm{FeCl}_{2}$, respectively, and attached on the surface of polycarboxyphenyl-grafted MWCNT (P-CNT) in aqueous medium. This approach shows a potential for enhancing the dispersion of $\mathrm{Fe}_{3} \mathrm{O}_{4}$ and $\mathrm{Sm}_{2} \mathrm{O}_{3}$ nanoparticles on the wall of P-CNT. The structure and morphological characteristics of the purified MWCNT, P-CNT, and metal oxide-anchored polycarboxyphenylgrafted MWCNT (MP-CNT) nanocomposites were studied by X-ray diffraction (XRD), scanning electron microscopy (SEM), transmission electron microscopy (TEM), and thermogravimetric analysis (TGA). The electrochemical performance of the purified MWCNT electrode, P-CNT electrode, and MP-CNT electrodes was tested by cyclic voltammetry (CV) and galvanostatic charge discharge in a $1.0 \mathrm{M} \mathrm{H}_{2} \mathrm{SO}_{4}$ aqueous electrolyte. The results showed that the specific capacitance of the purified MWCNT was $45.3 \mathrm{~F} / \mathrm{g}$ at the scan rate of $5 \mathrm{mV} / \mathrm{s}$ and increased to $54.1 \mathrm{~F} / \mathrm{g}$ after the modification with polycarboxyphenyl polymer. Further modification of P-CNT with $\mathrm{Sm}_{2} \mathrm{O}_{3}$ and $\mathrm{Fe}_{3} \mathrm{O}_{4}$ improved the specific capacitance of $65.84 \mathrm{~F} / \mathrm{g}$ and $173.38 \mathrm{~F} / \mathrm{g}$, respectively, at the same scan rate.

\section{Introduction}

With increasing the awareness for pollution control, industry and research centers around the world are searching for the possible alternatives to the development of renewable energy production for the replacement of fossil fuel [1, 2]. In this mission, supercapacitors can be an alternative to fulfill the rising demand of transferable power systems for electronics and automotive applications [3]. The two basic mechanisms for energy storage in supercapacitors are formations of electrical double layer (EDL) capacitance and pseudocapacitance [4]. The first one is a non-Faradic process in which charges are stored electrostatically via reversible ion absorption at the electrode electrolyte interface, while in the second type transformation of Faradic charge takes place at the electrode materials. Furthermore, supercapacitors store the energy in the electric field of the electrochemical double layer (Helmholtz Layer) at the electrode : electrolyte interface [5]. The positive and negative ionic charges within the electrolyte collect at the surface of the solid electrodes and balance for the electronic charge at the electrode surface. The concentration of the electrolyte and the size of the ions determine the thickness of the double layer in the range of 5-10 $\AA$ [4].

Demand of large supercapacitors with high voltage and improved energy and power density are under discussion for different applications [3]. Because of good thermal and chemical stability, high electrical conductivity, large surface 
area, porous structures, and long cycling stability of carbon nanomaterials, they are generally used as symmetric electrodes for EDL capacitors [5-7]. Furthermore, the specific surface area and functional groups of carbon nanomaterials impact the electrode performance. The electrode surface area can increase by using porous electrodes with an extremely large internal effective surface $[6,7]$. Intercalation of natural graphite and subsequent microwave irradiation can increase the surface area of graphite nanoplatelets [8]. Microwave irradiation of graphite oxide $[9,10]$ is also an effective way to increase the surface area of graphene sheets and resulting porous material shows high capacitance. Carbon nanomaterials have been also used to improve electrical, thermal, and mechanical properties of polymer nanocomposites [1115]. Multiwalled CNTs (MWNTs) showed limited specific capacitance, typically ranging from 10 to $100 \mathrm{~F} / \mathrm{g}$ [4-7]. Certain modification of MWCNT is essential to enhance the specific capacitance and energy density of MWCNT [16, 17]. Conducting polymers (e.g., polypyrrole, polyaniline (PANI), and polythiophene) [18-21] and metal oxides (e.g., $\mathrm{RuO}_{2}$, $\mathrm{Fe}_{2} \mathrm{O}_{3}, \mathrm{Bi}_{2} \mathrm{O}_{3}, \mathrm{MnO}_{2}$, and $\mathrm{Mn}_{3} \mathrm{O}_{4}$ ) [22-32] are accepted for pseudocapacitors with relatively high capacitance. During the charge-discharge process in conducting polymers and metal oxide, the generation of positively charged sites on the polymer chains and metal oxides creates structural deterioration with inferior cycling stability which, in turn, lowers the electrical conductivity of electrode [17]. To overcome the abovementioned problems, an appropriate stoichiometric combination of metal oxides or conducting polymers with carbonaceous materials have been used for the development of efficient supercapacitors [18, 21]. Many CNT/metal oxides composites have been reported as the electrochemical electrodes, which showed remarkable capacitance, much higher than those of pure CNT or individual metal oxides due to the prevention of the nanoparticles and CNT agglomeration by the anchored metal oxide nanoparticles on the wall of CNT [25, 28, 29]. Furthermore, the electron transmission across the metal oxides can also be improved by the well conductivity of CNT $[25,28]$.

Generally, an activated carbon electrode shows the rectangular shaped cyclic voltammogram $(\mathrm{CV})$ as an ideal capacitor. $\mathrm{RuO}_{2}$ and $\mathrm{IrO}_{2}$ also have an almost rectangular shaped $\mathrm{CV}$ and exhibit good capacitor behavior [24]. However, the shape of the $\mathrm{CV}$ is not an outcome of pure double layer charging but of a sequence of redox reactions occurring in the metallic oxide. Zheng and Jow [22] observed a very high specific capacitance of up to $750 \mathrm{~F} / \mathrm{g}$ for $\mathrm{RuO}_{2}$ prepared at relatively low temperatures. Kim and Park [28] reported the effects of nanosized $\mathrm{Fe}_{3} \mathrm{O}_{4}$ on supercapacitive properties of MWCNT. In their study, $\mathrm{Fe}_{3} \mathrm{O}_{4}$ nanoparticles were deposited by chemical coprecipitation of $\mathrm{Fe}^{2+}$ and $\mathrm{Fe}^{3+}$ in the presence of MWNTs in alkaline solutions in which a considerably superior specific capacitance of $\mathrm{Fe}_{3} \mathrm{O}_{4}$ dispersed MWCNT compared to that of the pure MWNT electrode was observed with retaining $85.1 \%$ of its initial capacitance over 1000 cycles. Kotal et al. [18] showed the effects on amidation of carbon nanofiber and, consequently, the grafting of PANI to obtain high capacitance and good cycling stability.
The synergistic combination of outstanding conducting properties of carbonaceous materials and high pseudocapacitance of conducting polymers and metal oxide can amalgamate for the development of high-performance supercapacitors. Though supercapacitors of carbon-based materials with conducting polymers are in their growing state [18, 21 ], there are not any reports that show the electrochemical properties of metal oxide decorated-conjugated polymergrafted-carbon nanomaterial composites. In this paper, a novel route to produce $\mathrm{Fe}_{2} \mathrm{O}_{3}$ and $\mathrm{Sm}_{2} \mathrm{O}_{3}$ particles-decorated polycarboxyphenyl-grafted MWCNT composite is developed at the first time by the grafting of polycarboxyphenyl group on the wall of MWCNT and subsequent oxidation of metal oxide precursor in an autoclave. Here, grafting of polycarboxyphenyl groups on MWCNT can not only develop long conjugated structure with MWCNT, but also reduce the aggregation of MWCNT. Furthermore, the anchoring of the metal oxide nanoparticles was assisted after grafting the polycarboxyphenyl group on the surface of MWCNT. The polycarboxyphenyl-grafted MWCNT leads to the development of a $\pi$-conjugated system and such a type of conducting network may facilitate the effective transfer of the Faradic charge through the MWCNT network. Then, the effect of the covalent functionalization as well as metal oxide decoration was compared for the electrochemical performance of the composites.

\section{Experimental}

2.1. Materials. Acetonitrile, azobisisobutyronitrile (AIBN), 4-aminobenzoic acid, sodium nitrite $\left(\mathrm{NaNO}_{2}\right)$, hydrochloric acid, tetrabutyl ammonium tetrafluoroborate $\left(\mathrm{NBu}_{4} \mathrm{BF}_{4}\right)$, ammonium sulfate, potassium persulfate, samarium nitrate, ferrous chloride, sulfuric acid, and nitric acid were of analytical reagent grade (Sigma-Aldrich) and were used as received. Pristine MWNT (CM-95) was supplied by Hanwha Nanotech Co., Ltd. (Korea). To prepare solutions for the experiments, water was purified in a Milli-Q Plus water purification system (Millipore Co. Ltd., USA).

\subsection{Synthesis of Polycarboxyphenyl-Grafted MWCNT (P-} CNT). Purified MWCNT was obtained after the treatment of pristine MWCNT with the mixture of concentrated sulfuric acid and nitric acid (1:1) and subsequent washing several times with deionized water. 4-Carboxyphenyl diazonium salt was prepared by diazotization as reported in our previous study [33]. Typically, the grafting of polycarboxyphenyl group on the wall of MWCNT was performed by dispersing $0.2 \mathrm{~g}$ of purified MWCNT in $40 \mathrm{~mL}$ of acetonitrile with continuous stirring for $4 \mathrm{~h}$, and carboxyphenyl diazonium salt $(1.0 \mathrm{~g})$ and AIBN (0.15 g) were added at room temperature. The reaction mixture was stirred for $12 \mathrm{~h}$ at $60^{\circ} \mathrm{C}$. Next, the reaction mixture was vacuum-filtered, washed with deionized water sufficiently, and finally dried in a vacuum oven at $70^{\circ} \mathrm{C}$ overnight. Here, the grafting of polycarboxyphenyl group on the MWCNT was controlled by adjusting the amount of diazonium salt in the synthesis medium. 


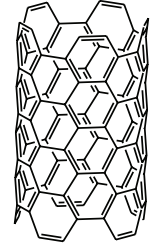

MWNT

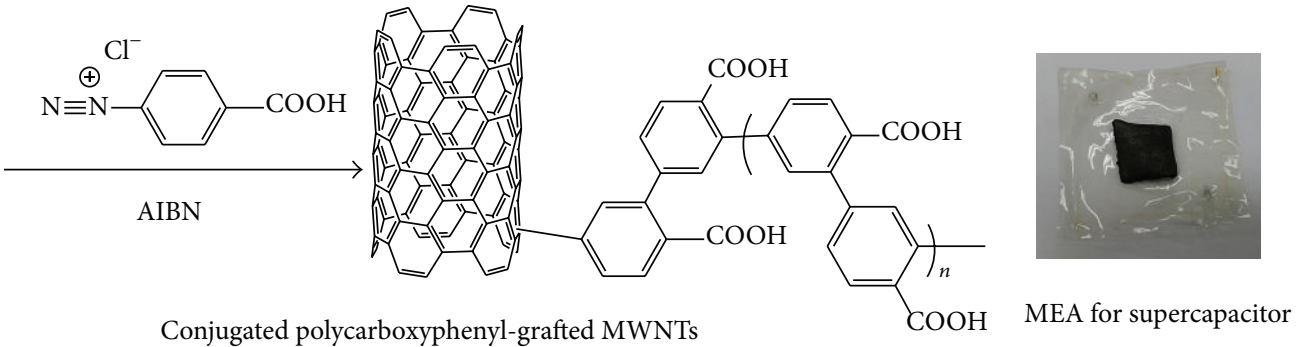

$(\mathrm{P}-\mathrm{CNT})$

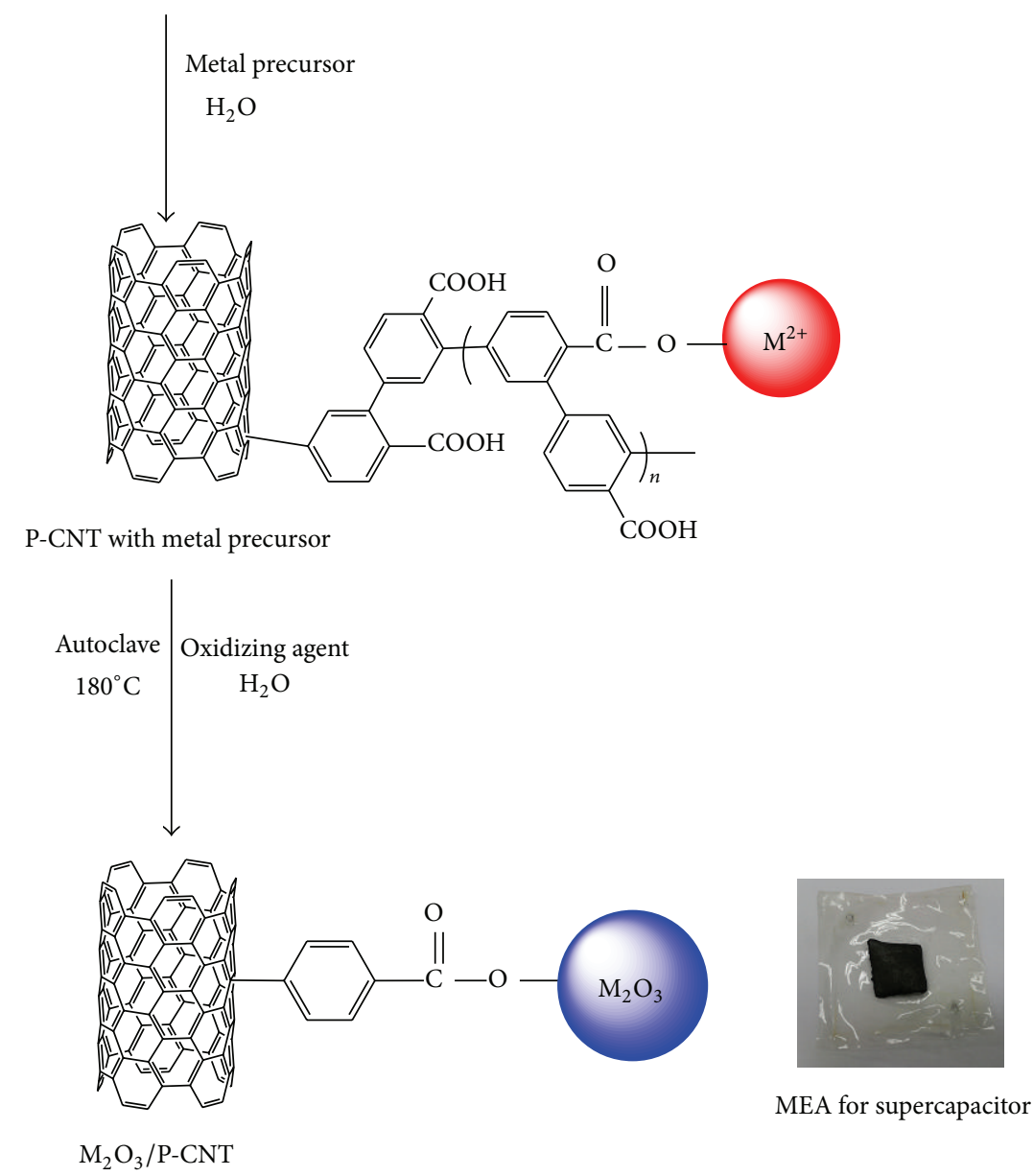

\footnotetext{
$\mathrm{M}: \mathrm{Sm} / \mathrm{Fe}$

Oxidizing agents: $\left(\mathrm{NH}_{4}\right) \mathrm{S}_{2} \mathrm{O}_{8} / \mathrm{K}_{2} \mathrm{~S}_{2} \mathrm{O}_{8}$

Metal precursors: $\mathrm{Sm}\left(\mathrm{NO}_{3}\right)_{3} / \mathrm{FeCl}_{2}$
}

FIGURE 1: Schematic diagrams for the grafting of conjugated polycarboxyphenyl polymer on the wall of MWCNT and subsequent decoration with metal oxide nanoparticles.

2.3. Synthesis of Metal Oxide-Anchored PolycarboxyphenylGrafted MWCNT (MP-CNT). Metal oxide nanoparticles were decorated onto the P-CNT in an autoclave using solution process. The P-CNT ( $0.2 \mathrm{~g})$ was mixed with the metal oxide precursor $(2 \mathrm{~g})$, oxidizing agent $(2 \mathrm{~g})$, and an excess of deionized water. The oxidizing agents, $\left(\mathrm{NH}_{4}\right) \mathrm{S}_{2} \mathrm{O}_{8}$ and $\mathrm{K}_{2} \mathrm{~S}_{2} \mathrm{O}_{8}$, were used for the oxidation of metal precursors, $\mathrm{Sm}\left(\mathrm{NO}_{3}\right)_{3}$ and $\mathrm{FeCl}_{2}$, respectively. The oxidation of metal precursors into metal oxides was performed in an autoclave along with $\mathrm{P}-\mathrm{CNT}$ at $180^{\circ} \mathrm{C}$ for $5 \mathrm{~h}$, and the resulting reaction mixture was filtered, washed with deionized water, and then dried in a vacuum oven at $70^{\circ} \mathrm{C}$ for $24 \mathrm{~h}$.

2.4. Characterization of Purified MWCNT, P-CNT, and MPCNT. An X-ray diffractometer (Rigaku, Japan, with $\mathrm{Cu}$ $\operatorname{KR}(\lambda=1.540 \AA)$ radiation) was used to measure the XRD patterns of purified MWCNT, P-CNT, and MP-CNT. Thermogravimetric analysis of purified MWCNT, P-CNT, 


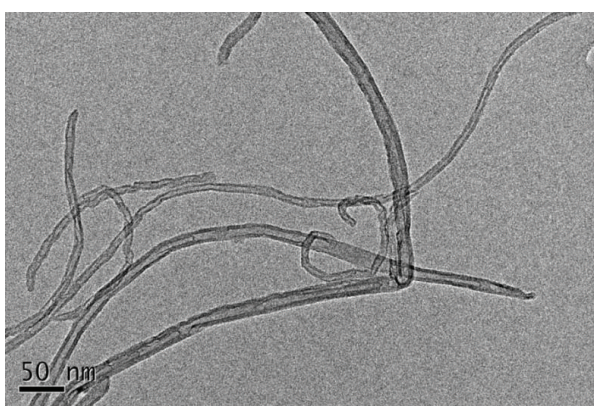

(a)

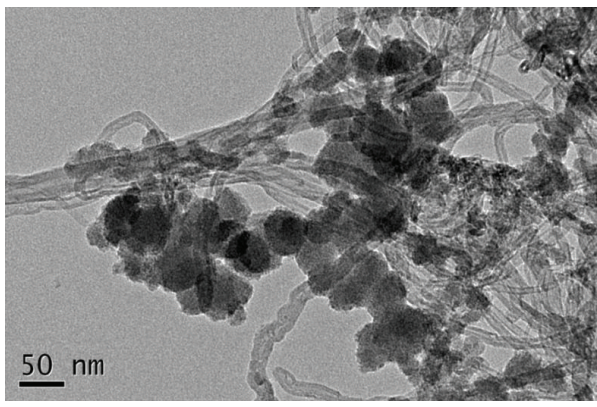

(c)

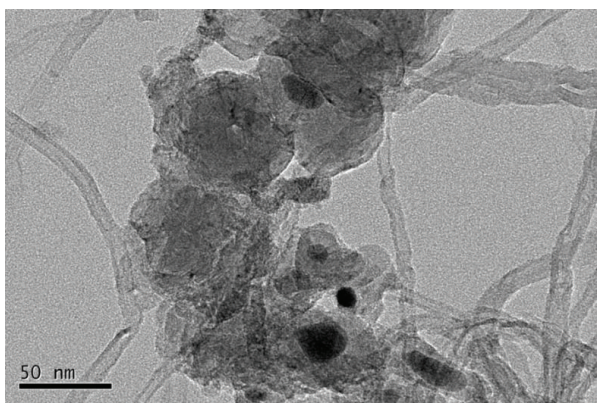

(e)

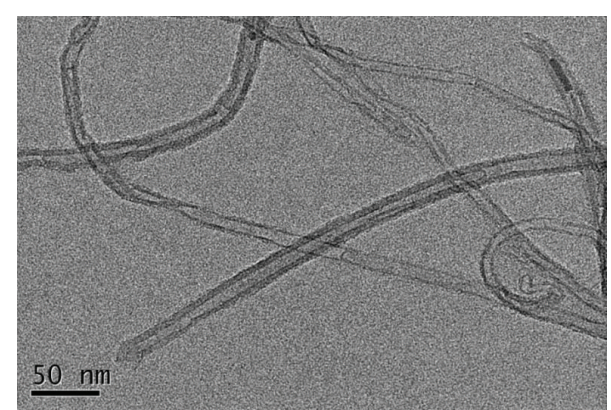

(b)

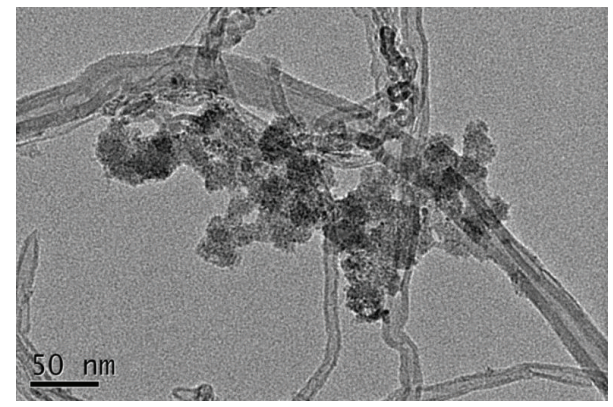

(d)

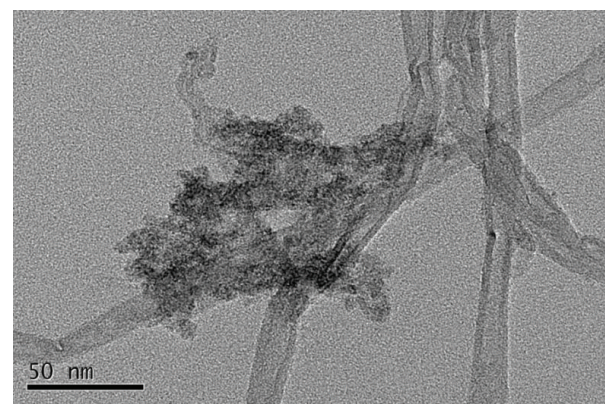

(f)

Figure 2: TEM images of (a) purified MWCNT, (b) P-CNT, (c) P-CNT with Sm $\left(\mathrm{NO}_{3}\right)_{3}$, (d) $\mathrm{Sm}_{2} \mathrm{O}_{3}$ nanoparticle decorated P-CNT, (e) P-CNT with $\mathrm{FeCl}_{2}$, and (f) $\mathrm{Fe}_{2} \mathrm{O}_{3}$ particle decorated P-CNT.

and MP-CNT was performed using a sinco TGA N-1000 with a heating rate of $10^{\circ} \mathrm{C} / \mathrm{min}$ under a nitrogen atmosphere. The morphological features of the electrode materials were observed with transmission electron microscopy (TEM, JEM-2100F, JEOL) and scanning electron microscopy (SEM, VEGA II SBH, Tescan). The sample for TEM measurement was prepared by ultrasonication of $\sim 0.01 \mathrm{mg} / \mathrm{mL}$ of the electrode materials in deionized water followed by dipping the TEM grid on colloidal suspension. Powder sample without dispersion in any solvent was used for SEM observation.

2.5. Electrochemical Measurements. A conventional twoelectrode configuration was used to study the electrochemical behavior of the prepared electrode materials (purified MWCNT, P-CNT, and MP-CNT) by cyclic voltammetry $(\mathrm{CV})$ and galvanostatic charge-discharge (GCD) measurements. Working electrode (cathode) was prepared by mixing $90 \%$ MWCNT, P-CNT, and MP-CNT individually with $10 \%$ Nafion solution as a binder. A small amount of isopropyl alcohol was added to obtain a more homogeneous dispersion. Then, the slurry was coated onto highly conductive hydrophobic carbon paper followed by a vacuum dry at $70^{\circ} \mathrm{C}$ for $24 \mathrm{~h}$. The mass of the as-synthesized electrode materials coated on the electrode was about $1 \mathrm{mg}$. Activated carbon electrode was used as anode and aqueous $\mathrm{H}_{2} \mathrm{SO}_{4}$ solution (1M) was used as the electrolyte. The applied potential range for $\mathrm{CV}$ and GCD was kept in the limits from 0.0 to $1.00 \mathrm{~V}$ because the decomposition voltage of $1 \mathrm{M}$ aqueous $\mathrm{H}_{2} \mathrm{SO}_{4}$ electrolyte is $\sim 1.4 \mathrm{~V}$.

\section{Results and Discussion}

Our approach covers the grafting of 4-carboxyphenyl diazonium salt on the wall of purified MWCNT to give carboxyphenyl-grafted MWCNT. The reaction of diazonium salt with the carboxyphenyl-grafted MWCNT and AIBN by free radical polymerization ultimately generated polycarboxyphenyl-grafted MWCNT (P-CNT). The carboxyl 


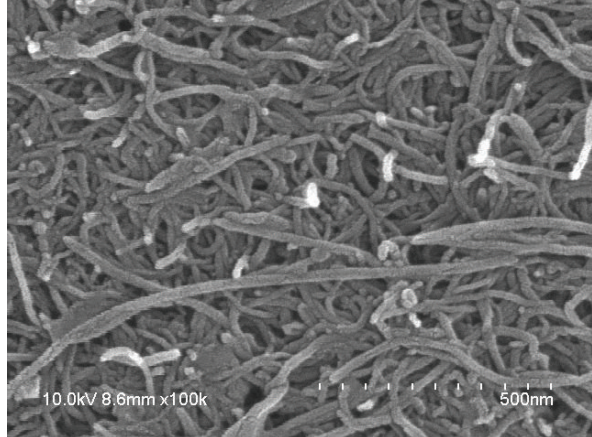

(a)

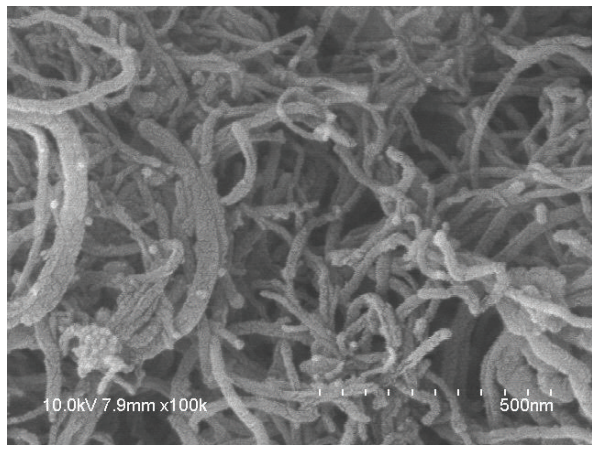

(c)

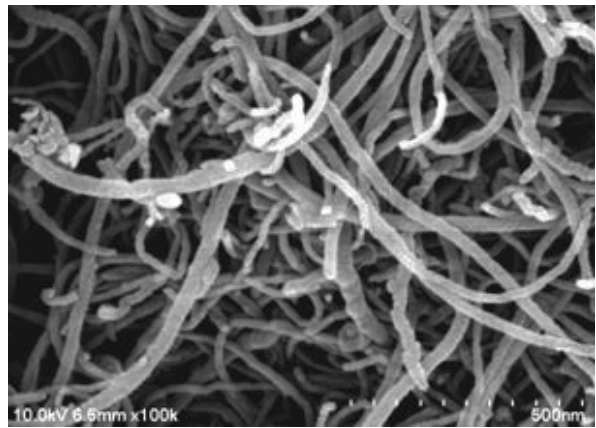

(e)

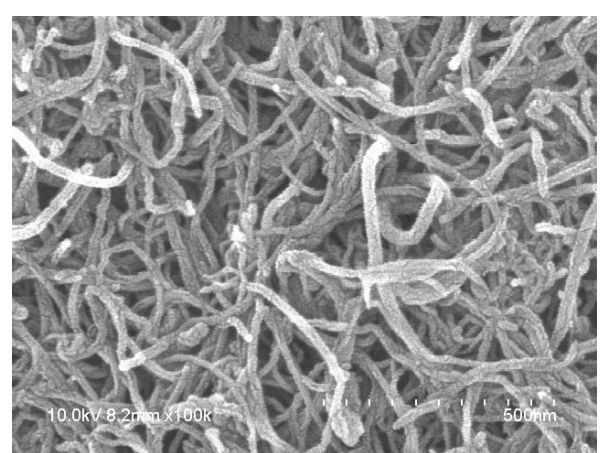

(b)

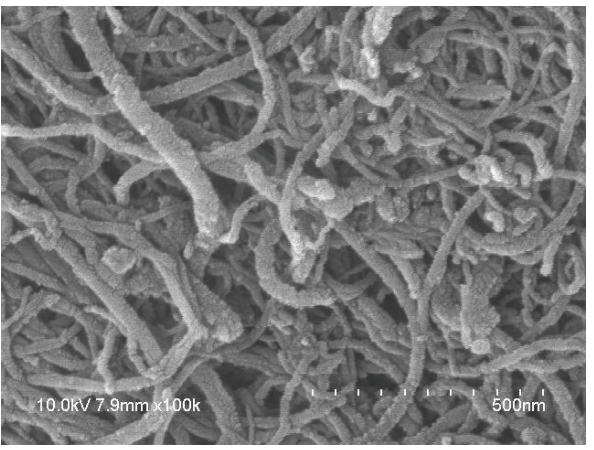

(d)

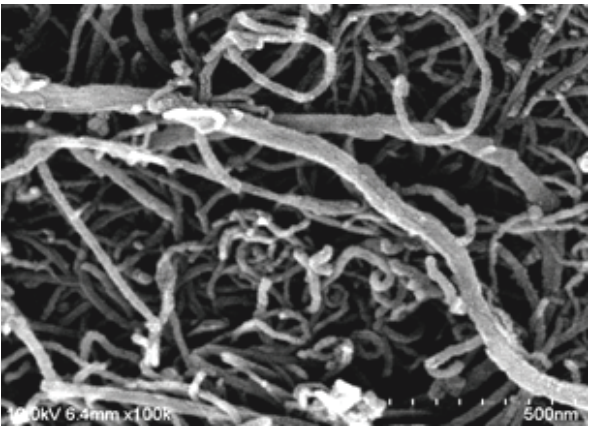

(f)

Figure 3: SEM images of (a) purified MWCNT, (b) P-CNT, (c) P-CNT with Sm $\left(\mathrm{NO}_{3}\right)_{3}$, (d) $\mathrm{Sm}_{2} \mathrm{O}_{3}$ nanoparticle decorated P-CNT, (e) P-CNT with $\mathrm{FeCl}_{2}$, and (f) $\mathrm{Fe}_{2} \mathrm{O}_{3}$ particle decorated P-CNT.

group on the diazonium salt also assisted in the polymerization, leading to the development of a $\pi$-conjugated system in $\mathrm{P}-\mathrm{CNT}$. Then, the P-CNT was subsequently reacted with the excess of metal precursors separately to produce a complex derivative on its surface, followed by oxidation of the metal precursor in the presence of oxidizing agent to form a MPCNT composite (Figure 1).

The morphologies of the surfaces, defects, and surface irregularities of purified MWCNT, P-CNT, and MP-CNT are the most important factors for evaluating the electrochemical properties. In this study, TEM and SEM were used to provide reliable and visual measurements about the surface morphologies of the electrode materials. Figure 2 shows the TEM images of the (a) purified MWCNT, (b) P-CNT, (c) PCNT with $\mathrm{Sm}\left(\mathrm{NO}_{3}\right)_{3}$, (d) $\mathrm{Sm}_{2} \mathrm{O}_{3} / \mathrm{P}-\mathrm{CNT}$, (e) P-CNT with $\mathrm{FeCl}_{2}$, and (f) $\mathrm{Fe}_{2} \mathrm{O}_{3} / \mathrm{P}-\mathrm{CNT}$. The $\mathrm{sp}^{2}$ hybridization state of carbon in MWCNT was not changed due to the grafting of conjugated polycarboxyphenyl polymer. Obviously, the diameter of P-CNT was observed greater in Figure 2(b) than the purified MWCNT in Figure 2(a) as a proof of the grafting of polycarboxyphenyl polymer. In our previous study, we have already reported the mechanism of the formation of polycarboxyphenyl-grafted MWCNT with plausible structures by the grafting of diazonium compound for the development of enzyme-free biosensors [33]. The morphological feature of the P-CNT with metal precursor was changed after the treatment with oxidizing agent. Here, the fine distribution of $\mathrm{Fe}_{2} \mathrm{O}_{3}$ nanoparticles was observed compared to $\mathrm{Sm}_{2} \mathrm{O}_{3}$ nanoparticles on the surface of P-CNT.

Figure 3 displays the SEM images of (a) purified MWCNT, (b) P-CNT, (c) P-CNT with $\mathrm{Sm}\left(\mathrm{NO}_{3}\right)_{3}$, (d) $\mathrm{Sm}_{2} \mathrm{O}_{3} /$ P-CNT, (e) P-CNT with $\mathrm{FeCl}_{2}$, and (f) $\mathrm{Fe}_{2} \mathrm{O}_{3} / \mathrm{P}-\mathrm{CNT}$. Similar to TEM images, grafting of polycarboxyphenyl polymer on MWCNT increased the diameter of MWCNT. Relatively, 


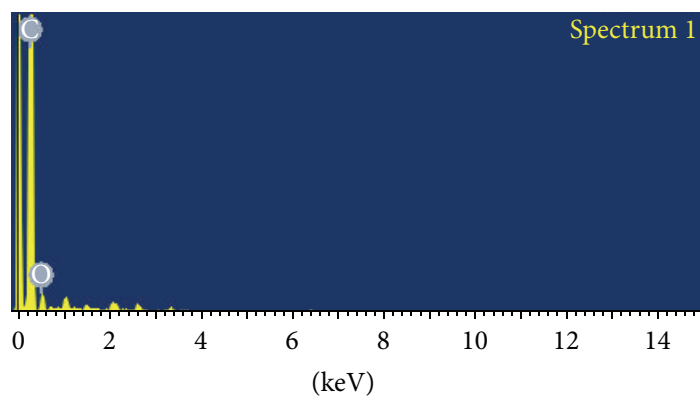

Full scale 1890 cts cursor: 0.000

(a)

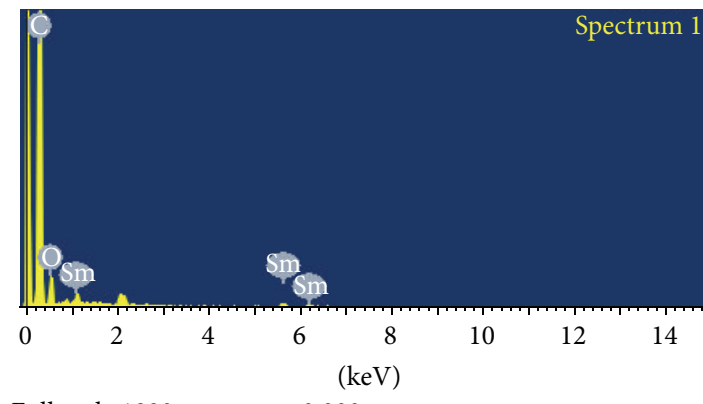

Full scale 1890 cts cursor: 0.000

(c)

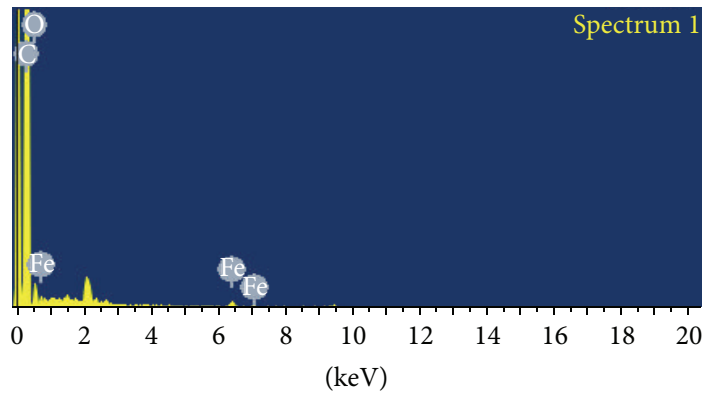

Full scale 640 cts cursor: 0.000

(e)

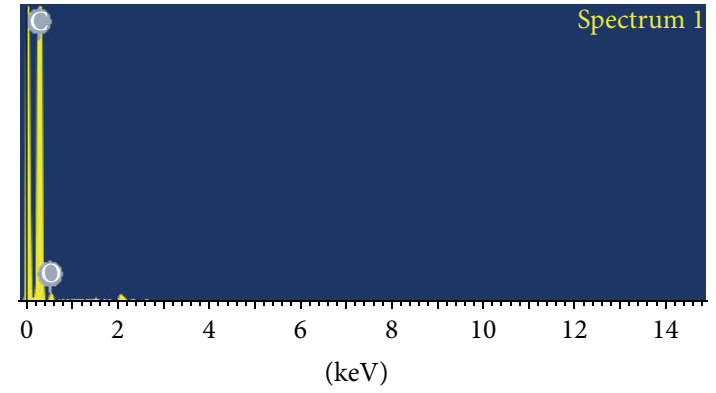

Full scale 1890 cts cursor: 0.000

(b)

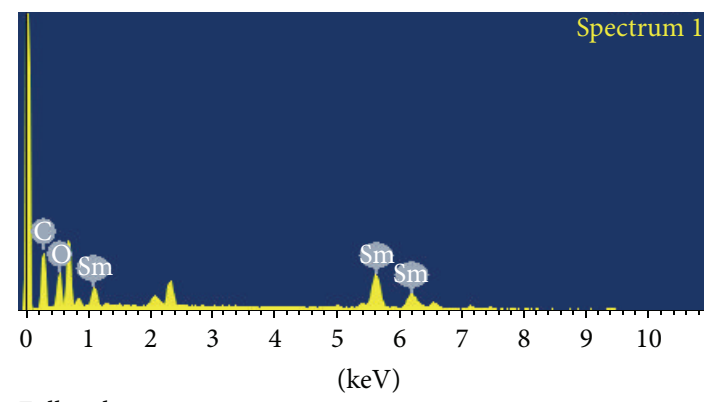

Full scale 2987 cts cursor: 0.000

(d)

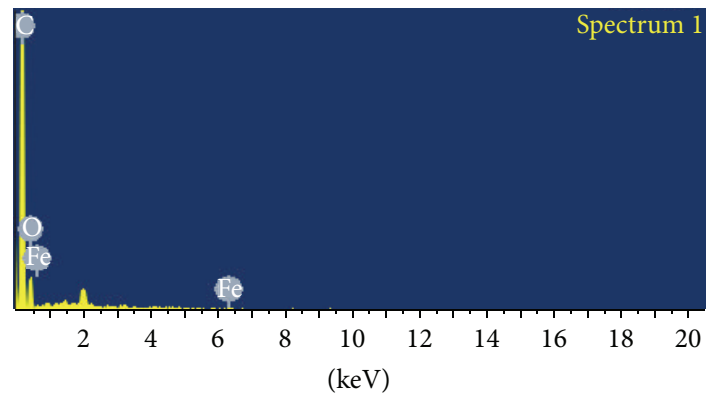

Full scale 630 cts cursor: 0.000

(f)

Figure 4: EDX spectra of (a) purified MWCNT, (b) P-CNT, (c) P-CNT with Sm(NO $\left.\mathrm{N}_{3}\right)_{3}$, (d) $\mathrm{Sm}_{2} \mathrm{O}_{3}$ nanoparticle decorated P-CNT, (e) P-CNT with $\mathrm{FeCl}_{2}$, and (f) $\mathrm{Fe}_{2} \mathrm{O}_{3}$ particle decorated P-CNT.

dense decoration of metal oxide nanoparticles on P-CNT was observed in $\mathrm{Sm}_{2} \mathrm{O}_{3} / \mathrm{P}$-CNT compared to $\mathrm{Fe}_{2} \mathrm{O}_{3} / \mathrm{P}-\mathrm{CNT}$ composite. Energy dispersive $\mathrm{X}$-ray (EDX) analysis in Figure 4 confirms that only carbon and oxygen are present in the analysis of (a) purified MWCNT and (b) P-CNT. After the reaction with metal precursors, Fe and $\mathrm{Sm}$ were also observed in Figures 4(c) and 4(e), respectively. The calculated atomic ratios of $\mathrm{Sm}$ to $\mathrm{O}$ in Figure $4(\mathrm{~d})$ and $\mathrm{Fe}$ to $O$ in Figure 4(f) are close to $2: 3$, which agree well with the stoichiometric ratio of $\mathrm{Fe}_{2} \mathrm{O}_{3}$ and $\mathrm{Sm}_{2} \mathrm{O}_{3}$. Figure 5(a) presents the $\mathrm{X}$-ray diffraction patterns of (A) purified MWCNT, (B) P-CNT, (C) P-CNT with $\mathrm{Sm}\left(\mathrm{NO}_{3}\right)_{3}$, and (D) $\mathrm{Sm}_{2} \mathrm{O}_{3} / \mathrm{P}-\mathrm{CNT}$. The diffraction peak of MWCNT at $2 \theta=26.1^{\circ}$ and $43.3^{\circ}$ was observed corresponding to the 002 and 100 , respectively. The $\mathrm{Sm}_{2} \mathrm{O}_{3} / \mathrm{P}-\mathrm{CNT}$ shows diffraction peaks at $222,321,024,332,422,125$, and 400 as the indication of the formation of $\mathrm{Sm}_{2} \mathrm{O}_{3}$ nanoparticle [34] on the surface of MWCNT. Figure 5(b) shows X-ray diffraction patterns of (A) purified MWCNT, (B) P-CNT, (C) P-CNT with $\mathrm{FeCl}_{2}$, and (D) $\mathrm{Fe}_{2} \mathrm{O}_{3}$ nanoparticles decorated P-CNT. Except for the characteristic diffraction peak of MWCNT, we could not observe any additional peak in P-CNT with $\mathrm{FeCl}_{2}$, but P-CNT with $\mathrm{Sm}\left(\mathrm{NO}_{3}\right)_{3}$ showed sharp diffraction peak at 102. Probably, the difference in the interaction of different metal precursors $\left(\mathrm{Sm}\left(\mathrm{NO}_{3}\right)_{3}\right.$ and $\mathrm{FeCl}_{2}$ ) with $\mathrm{P}-\mathrm{CNT}$ was responsible for showing such type of variation on the $\mathrm{X}$-ray diffraction peaks. Furthermore, $\mathrm{Fe}_{2} \mathrm{O}_{3} / \mathrm{P}-\mathrm{CNT}$ composite shows the diffraction peaks of $\mathrm{Fe}_{2} \mathrm{O}_{3}$ at 220, 311, 222, and 400 [35]. Here, the broader size of the diffractive peaks of $\mathrm{Fe}_{2} \mathrm{O}_{3}$ indicates that the crystalline size of $\mathrm{Fe}_{2} \mathrm{O}_{3}$ particles is quite small.

Figure 6(a) shows TGA thermograms of (A) purified MWCNT, (B) P-CNT, (C) P-CNT with $\mathrm{Sm}\left(\mathrm{NO}_{3}\right)_{3}$, and (D) $\mathrm{Sm}_{2} \mathrm{O}_{3} / \mathrm{P}$-CNT. Except for $\sim 3 \%$ mass loss below $60^{\circ} \mathrm{C}$, 


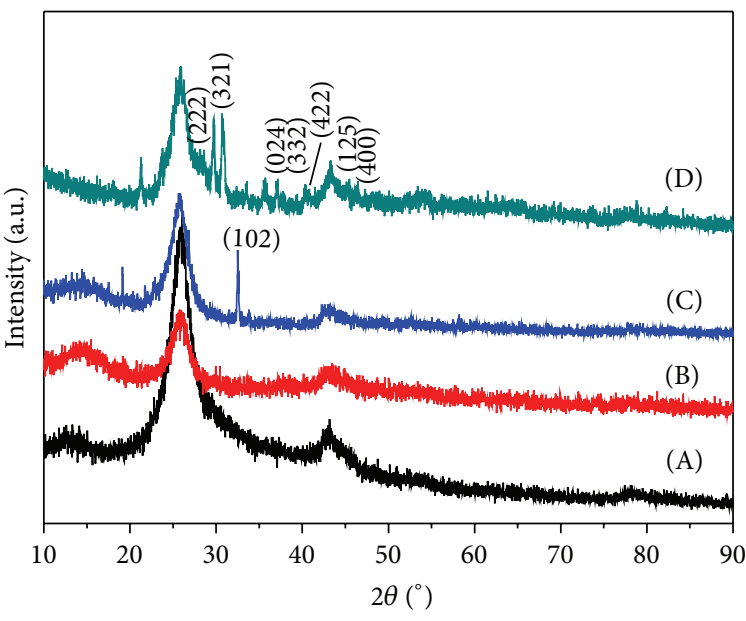

(a)

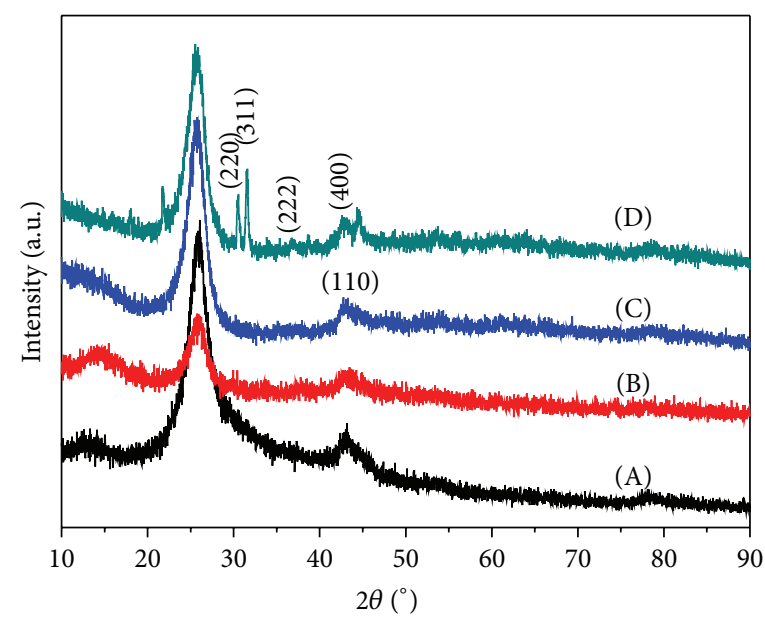

(b)

Figure 5: (a) The XRD patterns of (A) purified MWCNT, (B) P-CNT, (C) P-CNT with $\mathrm{Sm}\left(\mathrm{NO}_{3}\right)_{3}$, and (D) Sm $\mathrm{O}_{3}$ nanoparticles decorated P-CNT. (b) The XRD patterns of (A) purified MWCNT, (B) P-CNT, (C) P-CNT with $\mathrm{FeCl}_{2}$, and (D) $\mathrm{Fe}_{2} \mathrm{O}_{3}$ nanoparticles decorated P-CNT.

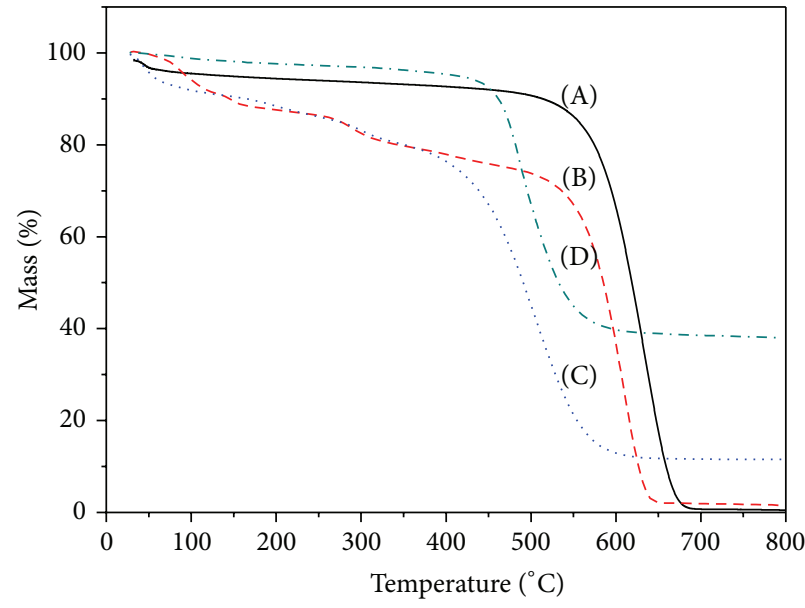

(a)

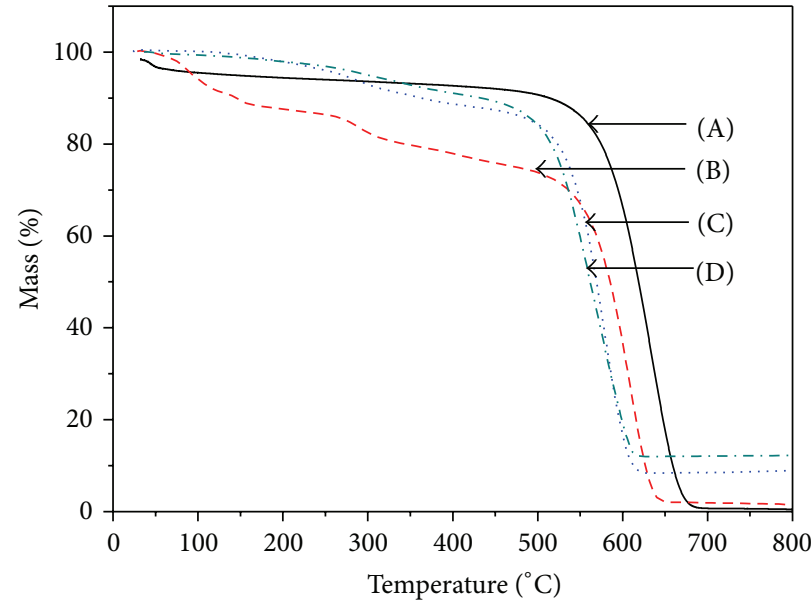

(b)

Figure 6: (a) TGA thermograms of (A) purified MWCNT, (B) P-CNT, (C) P-CNT with $\mathrm{Sm}\left(\mathrm{NO}_{3}\right)_{3}$, and (D) Sm ${ }_{2} \mathrm{O}_{3}$ nanoparticles decorated P-CNT. (b) TGA thermograms of (A) purified MWCNT, (B) P-CNT, (C) P-CNT with $\mathrm{FeCl}_{2}$, and (D) $\mathrm{Fe}_{2} \mathrm{O}_{3}$ nanoparticles decorated P-CNT.

purified MWCNT did not lose major mass before $\sim 500^{\circ} \mathrm{C}$, whereas P-CNT lost $16.3 \%$ mass in the two steps between 110 and $400^{\circ} \mathrm{C}$ and underwent a major mass loss ( $\left.65 \mathrm{wt} \%\right)$ at $\sim 500^{\circ} \mathrm{C}$. The mass loss of P-CNT below $400^{\circ} \mathrm{C}$ occurred due to the degradation of grafted polymer in MWCNT. Probably, the degradation of carboxyl group happened at the earlier stage and conjugated benzene rings at the later stage. Here, lower thermal stability of P-CNT than purified MWCNT was due to the grafting of long polymer chain on the wall of nanotube. Figure 6(b) presents TGA thermograms of (A) purified MWCNT, (B) P-CNT, (C) P-CNT with $\mathrm{FeCl}_{2}$, and (D) $\mathrm{Fe}_{2} \mathrm{O}_{3} / \mathrm{P}$-CNT. When we compared the TGA thermograms of MWCNT with metal precursor and metal oxide nanoparticles in Figures 6(a) and 6(b), obviously thermal stability of the metal oxide particle decorated P-CNT was higher than P-CNT with metal precursor. Interestingly, the residue after TGA of $\mathrm{Sm}_{2} \mathrm{O}_{3} / \mathrm{P}-\mathrm{CNT}$ and $\mathrm{Fe}_{2} \mathrm{O}_{3} / \mathrm{P}-\mathrm{CNT}$ was observed to be $\sim 40 \%$ and $\sim 12 \%$, respectively. The dense decoration of $\mathrm{Sm}_{2} \mathrm{O}_{3}$ nanoparticles than $\mathrm{Fe}_{2} \mathrm{O}_{3}$ on P-CNT was responsible for obtaining different nature of the TGA thermograms of $\mathrm{Sm}_{2} \mathrm{O}_{3} / \mathrm{P}-\mathrm{CNT}$ and $\mathrm{Fe}_{2} \mathrm{O}_{3} / \mathrm{P}-\mathrm{CNT}$ and that was also supported by the FESEM images in Figures 3(d) and 3(f).

The electrochemical performances of the purified MWCNT, P-CNT, $\mathrm{Sm}_{2} \mathrm{O}_{3} / \mathrm{P}-\mathrm{CNT}$, and $\mathrm{Fe}_{2} \mathrm{O}_{3} / \mathrm{P}-\mathrm{CNT}$ were analyzed using $\mathrm{CV}$ and GCD measurements. Figure 7(a) shows CV curves obtained in two-electrode cell for (A) purified MWCNT, (B) P-CNT, (C) $\mathrm{Sm}_{2} \mathrm{O}_{3} / \mathrm{P}-\mathrm{CNT}$ and (D) $\mathrm{Fe}_{2} \mathrm{O}_{3} / \mathrm{P}-\mathrm{CNT}$ electrodes at a voltage scan rate of $5 \mathrm{mV} / \mathrm{s}$ in $1.0 \mathrm{M} \mathrm{H}_{2} \mathrm{SO}_{4}$ electrolyte in potential ranges of 0.0 to $1.0 \mathrm{~V}$. From the above $\mathrm{CV}$ curves, the difference in the electrochemical surface activity of all electrode materials can easily be identified. It is noted that the area of the CV 


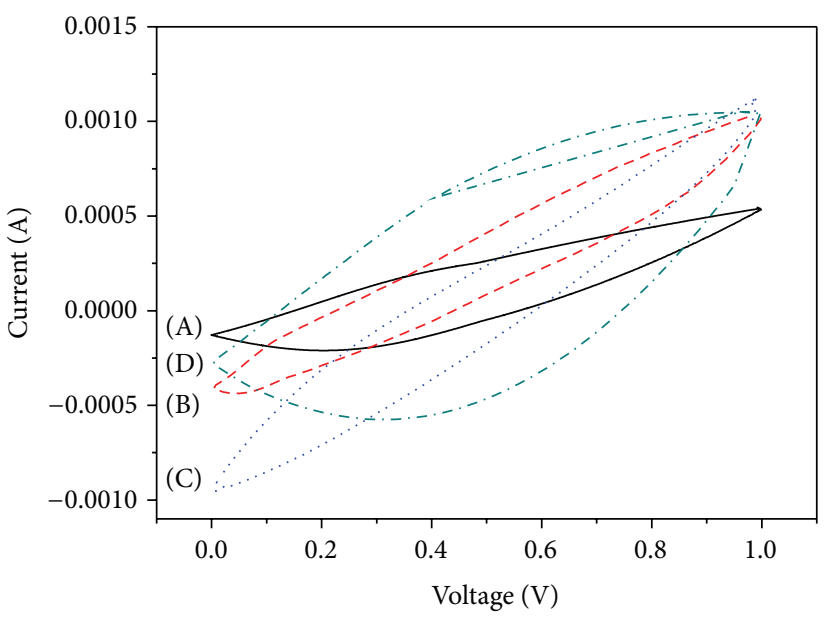

(a)

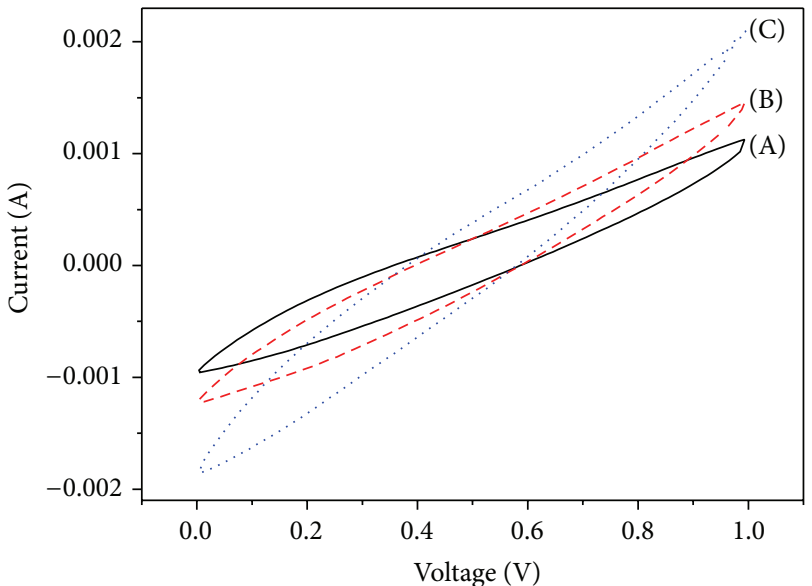

(b)

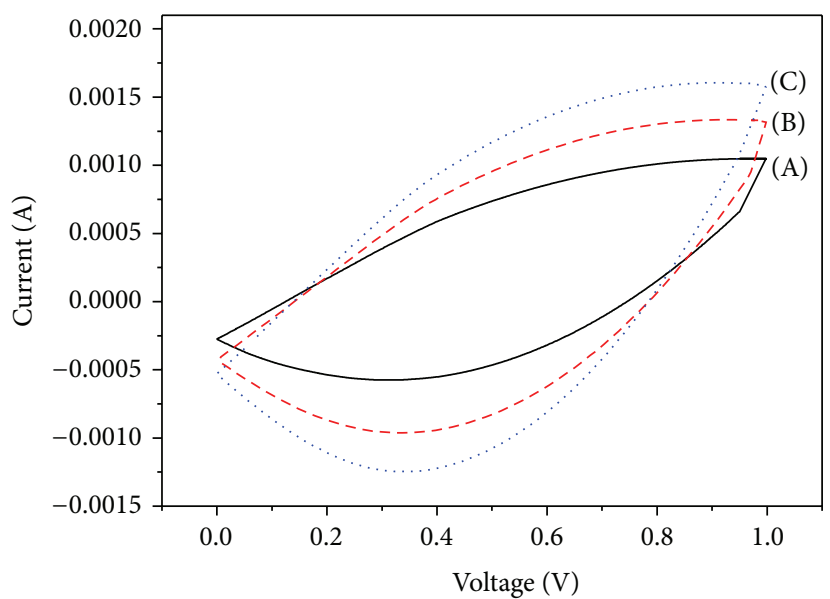

(c)

Figure 7: (a) Cyclic voltammograms of (A) purified MWNT, (B) P-CNT, (C) $\mathrm{Sm}_{2} \mathrm{O}_{3} / \mathrm{P}-\mathrm{CNT}$, and (D) $\mathrm{Fe}_{2} \mathrm{O}_{3} / \mathrm{P}-\mathrm{CNT}$ electrodes at a scan rate of $5 \mathrm{mV} \mathrm{s}^{-1}$ in $1.0 \mathrm{M} \mathrm{H}_{2} \mathrm{SO}_{4}$ electrolyte. (b) Cyclic voltammograms of $\mathrm{Sm}_{2} \mathrm{O}_{3} / \mathrm{P}$-CNT electrodes measured in $1.0 \mathrm{M} \mathrm{H}_{2} \mathrm{SO}_{4}$ electrolyte at the scan rates of (A) $5 \mathrm{mV} \mathrm{s}^{-1}$, (B) $10 \mathrm{mV} \mathrm{s}^{-1}$, and (C) $15 \mathrm{mV} \mathrm{s}^{-1}$. (c) Cyclic voltammograms of $\mathrm{Fe}_{2} \mathrm{O}_{3} / \mathrm{P}_{-} \mathrm{CNT}$ electrodes measured in $1.0 \mathrm{M} \mathrm{H}_{2} \mathrm{SO}_{4}$ electrolyte at the scan rates of (A) $5 \mathrm{mV} \mathrm{s}^{-1}$, (B) $10 \mathrm{mV} \mathrm{s}^{-1}$, and (C) $15 \mathrm{mV} \mathrm{s}^{-1}$.

curves of P-CNT is larger than that of purified MWCNT, indicating a better capacitive response of P-CNT. The grafting of conjugated polycarboxyphenyl group on MWCNT was useful for enhancing the capacitance performance. Significant synergistic effect of polycarboxyphenyl polymer and metal oxide was observed in metal oxide decorated P-CNT. Interestingly, $\mathrm{Fe}_{2} \mathrm{O}_{3}$ decorated P-CNT showed the largest capacity among all of the electrode materials without changing the shape of the CV profiles. Furthermore, P-CNT exhibited a much lower area of the CV curve than that of $\mathrm{Fe}_{2} \mathrm{O}_{3}$ and $\mathrm{Sm}_{2} \mathrm{O}_{3}$ decorated P-CNT, indicating the better capacitance performance of the metal decorated $\mathrm{P}-\mathrm{CNT}$ nanocomposite. Moreover, the intimate interaction or strong charge coupling of $\mathrm{Fe}_{2} \mathrm{O}_{3}$ with P-CNT arising from the chemical grafting provides a synergistic effect and results in enhanced accessibility of the electrolyte by every $\mathrm{Fe}_{2} \mathrm{O}_{3}$ nanoparticle, leading to improving capacitance of the $\mathrm{Fe}_{2} \mathrm{O}_{3} / \mathrm{P}$-CNT composites. On the contrary, dense decoration of $\mathrm{Sm}_{2} \mathrm{O}_{3}$ on the P-CNT results in agglomeration of metal particles and also decreases the effective surface area of $\mathrm{Sm}_{2} \mathrm{O}_{3} / \mathrm{P}-\mathrm{CNT}$ nanocomposite. As a result, the $\mathrm{Sm}_{2} \mathrm{O}_{3} / \mathrm{P}-$ CNT nanocomposite was the low specific capacitance. In this study, we could not observe any redox peaks in $\mathrm{P}-\mathrm{CNT}$ and MP-CNT probably due to the sequence of redox reactions occurring in the conjugated polymer and metallic oxide decorated MWCNT nanocomposite $[3,25]$. The area of the CV curves of $\mathrm{Sm}_{2} \mathrm{O}_{3} / \mathrm{P}-\mathrm{CNT}$ and $\mathrm{Fe}_{2} \mathrm{O}_{3} / \mathrm{P}$-CNT nanocomposites increased with increasing the scan rate from $5 \mathrm{mV} / \mathrm{s}$ to $15 \mathrm{mV} / \mathrm{s}$ as shown in Figures 7(b) and 7(c). Table 1 shows the specific capacitance of the purified MWCNT, P-CNT, $\mathrm{Sm}_{2} \mathrm{O}_{3} / \mathrm{P}-\mathrm{CNT}$, and $\mathrm{Fe}_{2} \mathrm{O}_{3} / \mathrm{P}-\mathrm{CNT}$ electrodes from cyclic voltammograms at a scan rate of $5 \mathrm{mV} / \mathrm{s}$. A Fe $\mathrm{O}_{3}$ decorated P-CNT composite electrode exhibited the highest specific capacitance $\left(173.3 \mathrm{Fg}^{-1}\right)$, almost 2.8 times higher than that of purified MWCNT electrode and 2.2 times higher than that of P-CNT electrode, indicating a significant 


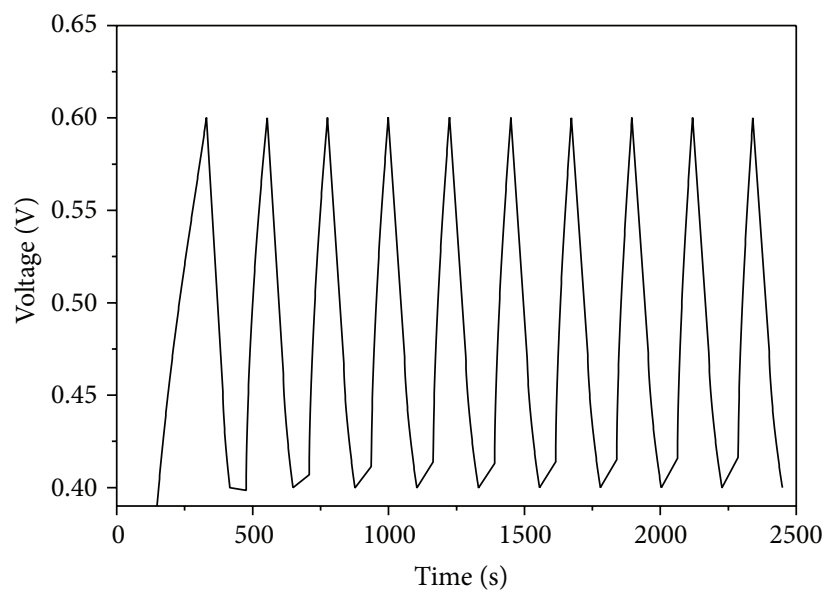

- MWNT

(a)

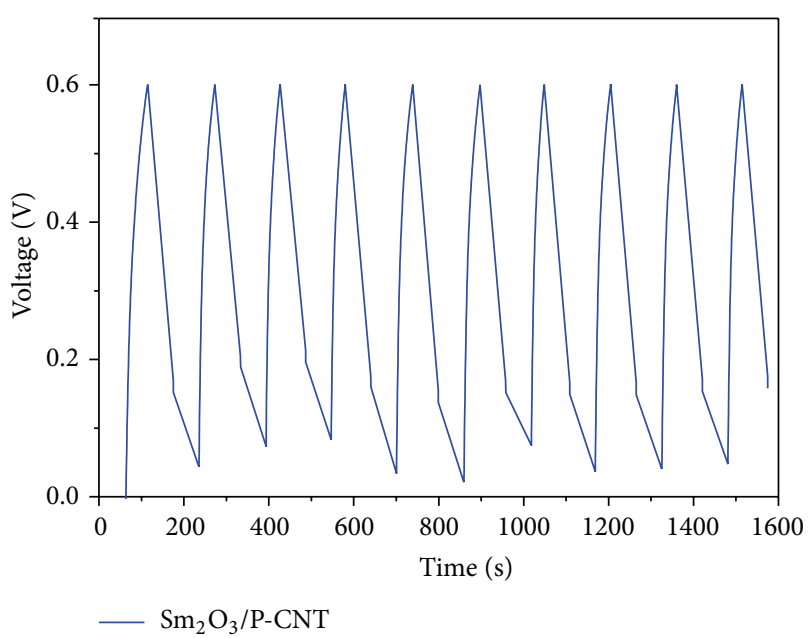

(c)

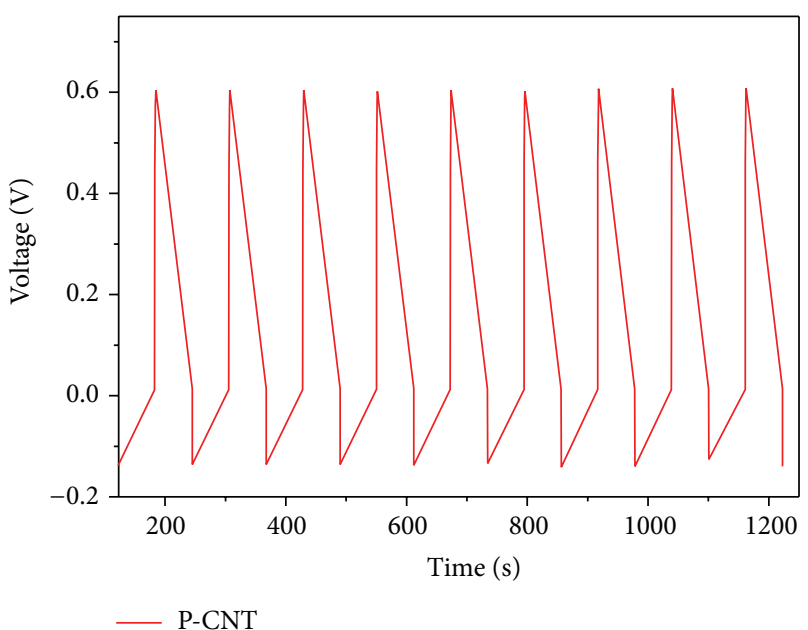

(b)

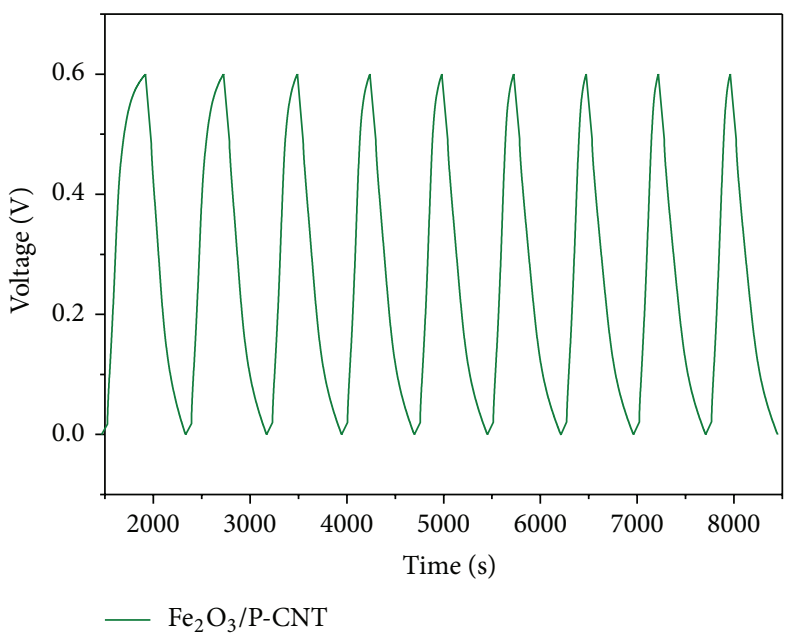

(d)

Figure 8: Galvanostatic charge discharge of (a) MWNT, (b) P-CNT (b), (c) $\mathrm{Sm}_{2} \mathrm{O}_{3} / \mathrm{P}-\mathrm{CNT}$, and (d) $\mathrm{Fe}_{2} \mathrm{O}_{3} / \mathrm{MWNT}$ at an applied constant current of $0.3 \mathrm{~mA}$ in $1.0 \mathrm{M} \mathrm{H}_{2} \mathrm{SO}_{4}$ aqueous electrolyte.

TABLE 1: Specific capacitance (F/g) of the purified MWNT, P-CNT, $\mathrm{Sm}_{2} \mathrm{O}_{3} / \mathrm{P}-\mathrm{CNT}$, and $\mathrm{Fe}_{2} \mathrm{O}_{3} / \mathrm{P}-\mathrm{CNT}$ electrodes from cyclic voltammograms at the scan rate of $5 \mathrm{mV} \mathrm{s}^{-1}$ in $1.0 \mathrm{M} \mathrm{H}_{2} \mathrm{SO}_{4}$ electrolyte.

\begin{tabular}{lcccc}
\hline & $\begin{array}{l}\text { Purified } \\
\text { MWNT }\end{array}$ & P-CNT & $\mathrm{Sm}_{2} \mathrm{O}_{3} / \mathrm{P}-\mathrm{CNT}$ & $\mathrm{Fe}_{2} \mathrm{O}_{3} / \mathrm{P}-\mathrm{CNT}$ \\
\hline $\begin{array}{l}\text { Specific } \\
\text { capacitance } \\
\left(\mathrm{Fg}^{-1}\right)\end{array}$ & 45.36 & 54.1 & 65.84 & 173.38 \\
\hline
\end{tabular}

synergistic effect of conjugated polymer and $\mathrm{Fe}_{2} \mathrm{O}_{3}$. The specific capacitance of the $\mathrm{Fe}_{2} \mathrm{O}_{3} / \mathrm{P}-\mathrm{CNT}$ composites was superior to that of $\mathrm{Sm}_{2} \mathrm{O}_{3} / \mathrm{P}-\mathrm{CNT}$, probably due to the different nature of metal oxides and their different interaction properties with $\mathrm{P}-\mathrm{CNT}$.

Figure 8 shows the GCD plots of (a) purified MWCNT, (b) P-CNT, (c) $\mathrm{Sm}_{2} \mathrm{O}_{3} / \mathrm{P}-\mathrm{CNT}$ and (d) $\mathrm{Fe}_{2} \mathrm{O}_{3} / \mathrm{P}-\mathrm{CNT}$ electrodes at an applied constant current of $0.3 \mathrm{~mA}$. It can be seen that the charge-discharge curves of the purified MWNTs were very symmetrical and had a triangular shape as shown in Figure 8(a). This implies that the purified MWNT electrodes clearly had electrochemical double layer capacitive behavior $[4,16]$. The P-CNT, $\mathrm{Sm}_{2} \mathrm{O}_{3} / \mathrm{P}-\mathrm{CNT}$, and $\mathrm{Fe}_{3} \mathrm{O}_{4} / \mathrm{P}-\mathrm{CNT}$ composite electrodes also showed reversible charge-discharge process of the electrode. Compared to the other electrode materials, $\mathrm{Fe}_{3} \mathrm{O}_{4} / \mathrm{P}$-CNT composite electrode showed the longest discharge time ascribed to the correct quantity of $\mathrm{Fe}_{2} \mathrm{O}_{3}$ contributing reversible redox transitions relating the exchange of protons and/or cations with the electrolyte.

\section{Conclusions}

The grafting of polycarboxyphenyl group on MWCNT and decoration with $\mathrm{Fe}_{2} \mathrm{O}_{3}$ and $\mathrm{Sm}_{2} \mathrm{O}_{3}$ nanoparticles separately presented herein offer a promising and facile approach to prepare a new class of electrode materials. The TEM, SEM, 
EDX, TGA, and X-ray diffraction of electrode materials provide the evidences for the grafting of polycarboxyphenyl group on the wall of MWCNT and subsequent metal oxide nanoparticles decoration. Electrochemical test of the purified MWCNT, P-CNT, $\mathrm{Sm}_{2} \mathrm{O}_{3} / \mathrm{P}-\mathrm{CNT}$, and $\mathrm{Fe}_{2} \mathrm{O}_{3} / \mathrm{P}-\mathrm{CNT}$ electrodes from cyclic voltammograms at a scan rate of $5 \mathrm{mV} / \mathrm{s}$ shows specific capacitance of $45.3 \mathrm{~F} / \mathrm{g}, 54.1 \mathrm{~F} / \mathrm{g}, 65.84 \mathrm{~F} / \mathrm{g}$, and $173.3 \mathrm{~F} / \mathrm{g}$, respectively. The remarkably highest specific capacitance of $\mathrm{Fe}_{2} \mathrm{O}_{3} / \mathrm{P}-\mathrm{CNT}$ composite electrode compared to other electrodes is due to the grafting of the conjugated polycarboxyphenyl polymer on MWCNTs in the development of a $\pi$-conjugated structure and proper decoration of P-CNT by $\mathrm{Fe}_{2} \mathrm{O}_{3}$ nanoparticles for the charge transfer facilitation.

\section{Conflict of Interests}

The authors declare that there is no conflict of interests regarding the publication of this paper.

\section{Acknowledgments}

This work was supported by the National Research Foundation of Korea Grant funded by the Korean Government (NRF-2013M1A3A3A02041878 and 20131510200400). The authors are grateful for the support by the Nuclear Power Core Technology Development Program of the Korea Institute of Energy Technology Evaluation and Planning (KETEP) granted financial resource from the Ministry of Trade, Industry \& Energy, Republic of Korea (Project no. 20131510200400).

\section{References}

[1] P. G. Bruce, S. A. Freunberger, L. J. Hardwick, and J.-M. Tarascon, "Li-O $\mathrm{O}_{2}$ and $\mathrm{Li}-\mathrm{S}$ batteries with high energy storage," Nature Materials, vol. 11, pp. 19-29, 2012.

[2] B. Dunn, H. Kamath, and J. M. Tarascon, "Electrical energy storage for the grid: a battery of choices," Science, vol. 334, no. 6058, pp. 928-935, 2011.

[3] L. L. Zhang and X. S. Zhao, "Carbon-based materials as supercapacitor electrodes," Chemical Society Reviews, vol. 38, no. 9, pp. 2520-2531, 2009.

[4] R. Kötz and M. Carlen, "Principles and applications of electrochemical capacitors," Electrochimica Acta, vol. 45, no. 15-16, pp. 2483-2498, 2000.

[5] J.-S. Ye, X. Liu, H. F. Cui, W.-D. Zhang, F.-S. Sheu, and T. M. Lim, "Electrochemical oxidation of multi-walled carbon nanotubes and its application to electrochemical double layer capacitors," Electrochemistry Communications, vol. 7, no. 3, pp. 249-255, 2005.

[6] J. Chmiola, G. Yushin, Y. Gogotsi, C. Portet, P. Simon, and P. L. Taberna, "Anomalous increase in carbon at pore sizes less than 1 nanometer," Science, vol. 313, no. 5794, pp. 1760-1763, 2006.

[7] Y. Zhai, Y. Dou, D. Zhao, P. F. Fulvio, R. T. Mayes, and S. Dai, "Carbon materials for chemical capacitive energy storage," Advanced Materials, vol. 23, no. 42, pp. 4828-4850, 2011.
[8] Q.-T. Truong, P. Pokharel, G. S. Song, and D.-S. Lee, "Preparation and characterization of graphene nanoplatelets from natural graphite via intercalation and exfoliation with tetraalkylammoniumbromide," Journal of Nanoscience and Nanotechnology, vol. 12, no. 5, pp. 4305-4308, 2012.

[9] P. Pokharel, Q.-T. Truong, and D. S. Lee, "Multi-step microwave reduction of graphite oxide and its use in the formation of electrically conductive graphene/epoxy composites," Composites Part B: Engineering, vol. 64, pp. 187-193, 2014.

[10] Y. Zhu, S. Murali, M. D. Stoller, A. Velamakanni, R. D. Piner, and R. S. Ruoff, "Microwave assisted exfoliation and reduction of graphite oxide for ultracapacitors," Carbon, vol. 48, no. 7, pp. 2118-2122, 2010.

[11] P. Pokharel and D. S. Lee, “Thermal and mechanical properties of reduced graphene oxide/polyurethane nanocomposite," Journal of Nanoscience and Nanotechnology, vol. 14, no. 8, pp. 57185721, 2014.

[12] P. Pokharel, H. Bae, J.-G. Lim, K. Y. Lee, and S. Choi, "Effects of titanate treatment on morphology and mechanical properties of graphene nanoplatelets/high density polyethylene nanocomposites," Journal of Applied Polymer Science, vol. 132, no. 23, 2015.

[13] P. Pokharel and D. S. Lee, "High performance polyurethane nanocomposite films prepared from a masterbatch of graphene oxide in polyether polyol," Chemical Engineering Journal, vol. 253, pp. 356-365, 2014.

[14] P. Pokharel, S. Choi, and D. S. Lee, "The effect of hard segment length on the thermal and mechanical properties of polyurethane/graphene oxide nanocomposites," Composites Part A: Applied Science and Manufacturing, vol. 69, pp. 168-177, 2015.

[15] P. Pokharel, S. H. Lee, and D. S. Lee, “Thermal, mechanical, and electrical properties of graphene nanoplatelet/graphene oxide/ polyurethane hybrid manocomposite," Journal of Nanoscience and Nanotechnology, vol. 15, no. 1, pp. 211-214, 2015.

[16] A. G. Pandolfo and A. F. Hollenkamp, "Carbon properties and their role in supercapacitors," Power Sources, vol. 157, no. 1, pp. 11-27, 2006.

[17] B. E. Conway, Electrochemical Supercapacitors: Scientific Fundamentals and Technological Applications, Kluwer-Plenum, New York, NY, USA, 1999.

[18] M. Kotal, A. K. Thakur, and A. K. Bhowmick, "Polyanilinecarbon nanofiber composite by a chemical grafting approach and its supercapacitor application," ACS Applied Materials and Interfaces, vol. 5, no. 17, pp. 8374-8386, 2013.

[19] Y. Huanga, J. Taob, W. Menga et al., "Super-high rate stretchable polypyrrole-based supercapacitors with excellent cycling stability," Nano Energy, vol. 11, pp. 518-525, 2015.

[20] Q.-F. Wu, K.-X. He, H.-Y. Mi, and X.-G. Zhang, "Electrochemical capacitance of polypyrrole nanowire prepared by using cetyltrimethylammonium bromide (CTAB) as soft template," Materials Chemistry and Physics, vol. 101, no. 2-3, pp. 367-371, 2007.

[21] E. Hür, G. A. Varol, and A. Arslan, "The study of polythiophene, poly(3-methylthiophene) and poly(3,4-ethylenedioxythiophene) on pencil graphite electrode as an electrode active material for supercapacitor applications," Synthetic Metals, vol. 184, pp. 16-22, 2013.

[22] J. P. Zheng and T. R. Jow, "High energy and high power density electrochemical capacitors," Journal of Power Sources, vol. 62, no. 2, pp. 155-159, 1996.

[23] C.-C. Hu, K.-H. Chang, M.-C. Lin, and Y.-T. Wu, "Design and tailoring of the nanotubular arrayed architecture of hydrous 
$\mathrm{RuO}_{2}$ for next generation supercapacitors," Nano Letters, vol. 6, no. 12, pp. 2690-2695, 2006.

[24] C. C. Hu, K. H. Chang, M. C. Lin, and Y. T. Wu, "Design and tailoring of the nanotubular arrayed architecture of hydrous $\mathrm{RuO}_{2}$ for next generation supercapacitors," Nano Letters, vol. 6, no. 12, pp. 2690-2695, 2006.

[25] A. L. M. Reddy and S. Ramaprabhu, "Nanocrystalline metal oxides dispersed multiwalled carbon nanotubes as supercapacitor electrodes," The Journal of Physical Chemistry C, vol. 111, no. 21, pp. 7727-7734, 2007.

[26] J. Chen, K. Huang, and S. Liu, "Hydrothermal preparation of octadecahedron $\mathrm{Fe} 3 \mathrm{O} 4$ thin film for use in an electrochemical supercapacitor," Electrochimica Acta, vol. 55, no. 1, pp. 1-5, 2009.

[27] D. Xuan, W. Chengyang, C. Mingming, J. Yang, and W. Jin, "Electrochemical performances of nanoparticle $\mathrm{Fe}_{3} \mathrm{O}_{4}$ / activated carbon supercapacitor using $\mathrm{KOH}$ electrolyte solution," Journal of Physical Chemistry C, vol. 113, no. 6, pp. 26432646, 2009.

[28] Y.-H. Kim and S.-J. Park, "Roles of nanosized $\mathrm{Fe}_{3} \mathrm{O}_{4}$ on supercapacitive properties of carbon nanotubes," Current Applied Physics, vol. 11, no. 3, pp. 462-466, 2011.

[29] L. Fang, B. Zhang, W. Li, J. Zhang, K. Huang, and Q. Zhang, "Fabrication of highly dispersed $\mathrm{ZnO}$ nanoparticles embedded in graphene nanosheets for high performance supercapacitors," Electrochimica Acta, vol. 148, pp. 164-169, 2014.

[30] F.-L. Zheng, G.-R. Li, Y.-N. Ou, Z.-L. Wang, C.-Y. Su, and Y.$\mathrm{X}$. Tong, "Synthesis of hierarchical rippled $\mathrm{Bi}_{2} \mathrm{O}_{3}$ nanobelts for supercapacitor applications," Chemical Communications, vol. 46, no. 27, pp. 5021-5023, 2010.

[31] G. X. Wang, B. L. Zhang, Z. L. Yu, and M. Z. Qu, "Manganese oxide/MWNTs composite electrodes for supercapacitors," Solid State Ionics, vol. 176, no. 11-12, pp. 1169-1174, 2005.

[32] R. Liu, J. Duay, and S. B. Lee, "Heterogeneous nanostructured electrode materials for electrochemical energy storage," Chemical Communications, vol. 47, no. 5, pp. 1384-1404, 2011.

[33] D.-J. Chunga, S.-H. Ohb, S. Komathic, A. I. Gopalanc, K.-P. Lee, and S.-H. Choi, "One-step modification of various electrode surfaces using diazonium salt compounds and the application of this technology to electrochemical DNA (E-DNA) sensors," Electrochimica Acta, vol. 76, pp. 394-403, 2012.

[34] B. Renganathan, D. Sastikumar, R. Srinivasan, and A. R. Ganesan, "Nanocrystalline samarium oxide coated fiber optic gas sensor," Materials Science and Engineering B: Solid-State Materials for Advanced Technology, vol. 186, no. 1, pp. 122-127, 2014.

[35] L.-F. Chen, Z.-Y. Yu, X. Ma, Z.-Y. Li, and S.-H. Yu, "In situ hydrothermal growth of ferric oxides on carbon cloth for lowcost and scalable high-energy-density supercapacitors," Nano Energy, vol. 9, pp. 345-354, 2014. 

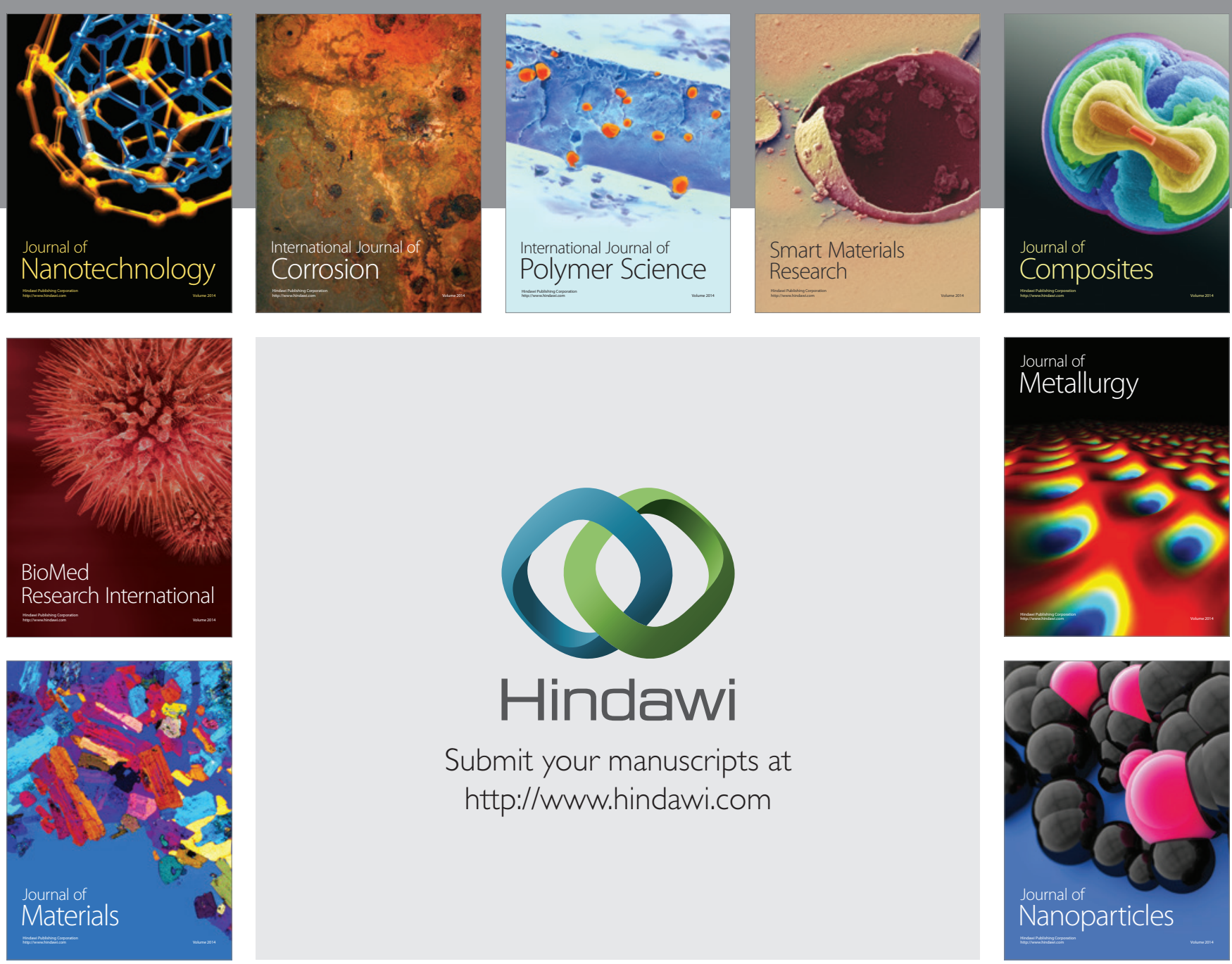

Submit your manuscripts at http://www.hindawi.com
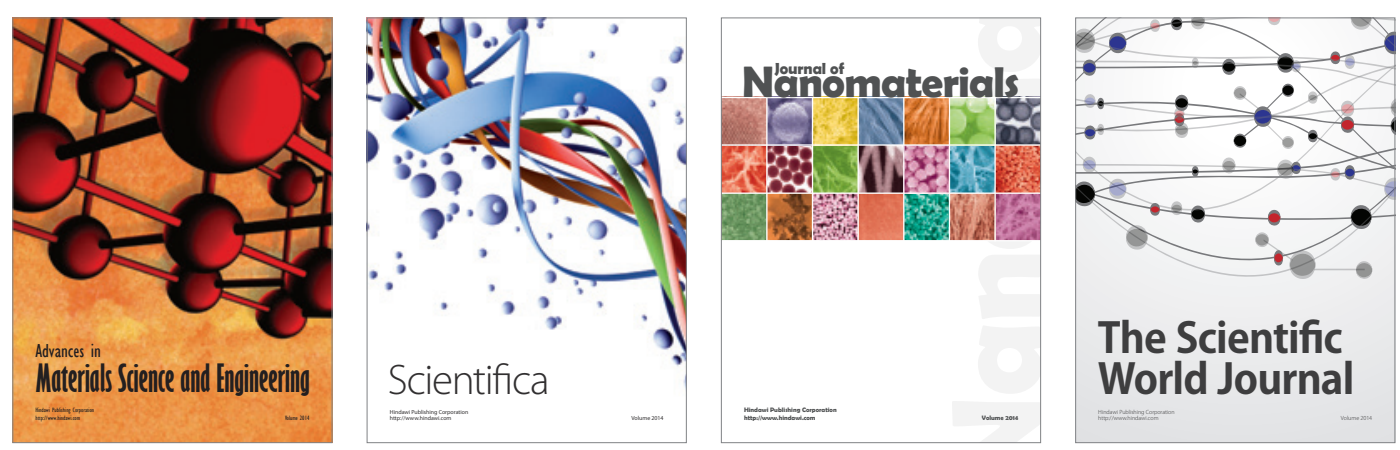

\section{The Scientific World Journal}
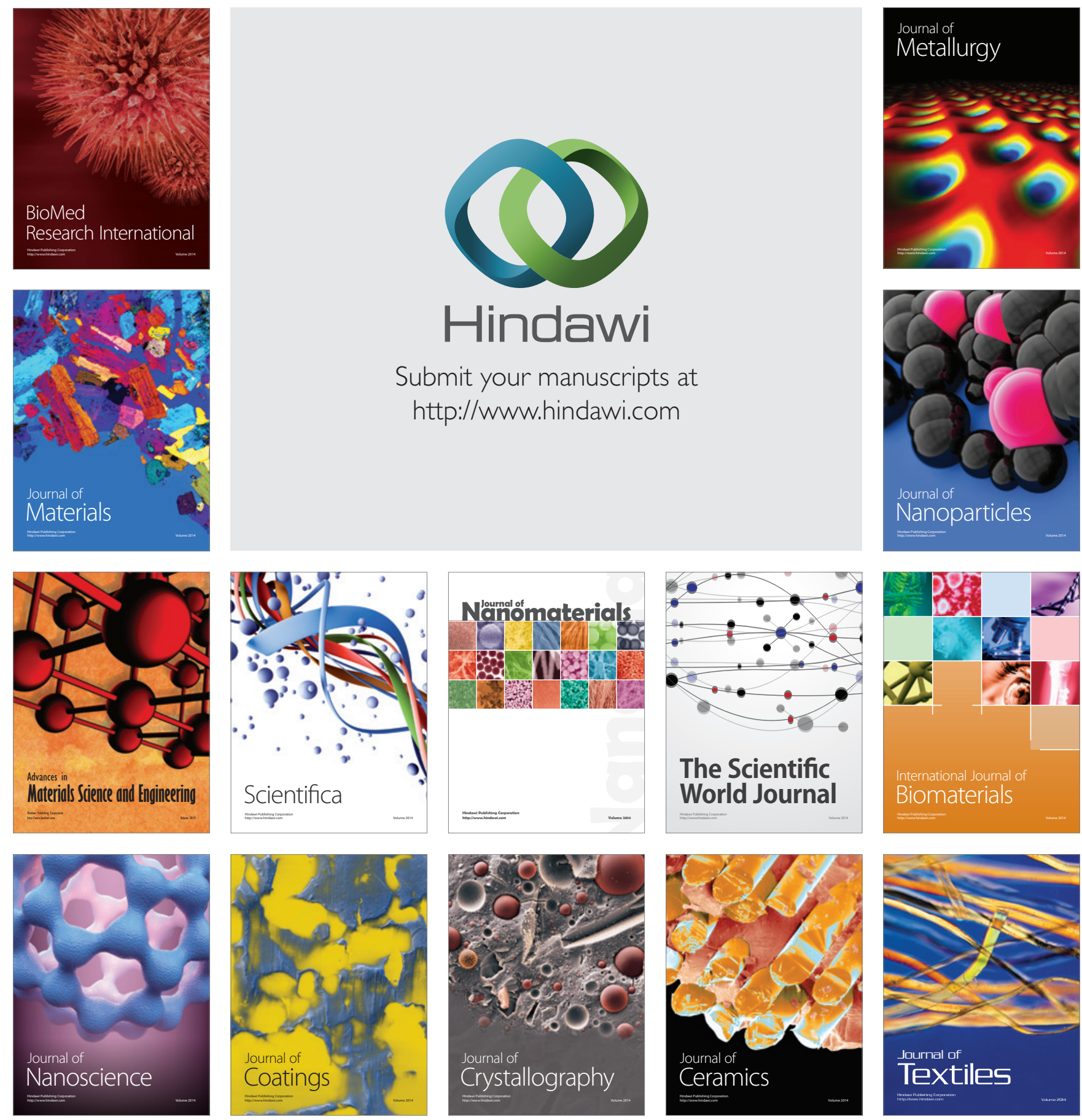